CLINICAL STUDY

\title{
Metabolic syndrome and the effect of testosterone treatment in young men with congenital hypogonadotropic hypogonadism
}

\author{
A Sonmez ${ }^{1}$, C Haymana ${ }^{2}, \mathrm{E}$ Bolu ${ }^{1}$, A Aydogdu ${ }^{1}, \mathrm{~S} \operatorname{Tapan}^{3}, \mathrm{M} \mathrm{Serdar}^{3}$, B Altun ${ }^{2}, \mathrm{C}$ Barcin $^{4}$, A Taslipinar ${ }^{1}$, \\ C Meric ${ }^{1}$, G Uckaya ${ }^{1}$ and M Kutlu ${ }^{1}$ \\ Departments of ${ }^{1}$ Endocrinology, ${ }^{2}$ Internal Medicine, ${ }^{3}$ Biochemistry and ${ }^{4}$ Cardiology, Gulhane School of Medicine, O6018 Etlik, Ankara, Turkey \\ (Correspondence should be addressed to A Sonmez; Email: alpersonmez@yahoo.com)
}

\begin{abstract}
Objective: The relationship between metabolic syndrome (MS) and hypogonadism has always been investigated in study groups confounded with aging, obesity or chronic metabolic disorders. So far, there has been no data about the presence of MS in young hypogonadal patients. Also, there is controversial data about the metabolic effects of testosterone replacement therapy. We investigated the frequency of MS in treatment-naïve, young men with congenital hypogonadal hypogonadism $(\mathrm{CHH})$. We also searched for the effect of testosterone replacement on the metabolic profiles of this specific patient group. Design: Retrospective analysis.

Methods: A total of 332 patients (age 21.68 \pm 2.09 years) were enrolled. The control group included 395 age- and body mass index (BMI)-matched healthy young men (age $21.39 \pm 1.49$ years). Standard regimen of testosterone esters $(250 \mathrm{mg} / 3$ weeks) was given to 208 patients.

Results: MS was more prevalent in $\mathrm{CHH}(P<0.001)$ according to healthy controls. The patients had higher arterial blood pressure, waist circumference (WC), triglyceride $(P<0.001$ for all), fasting glucose $(P=0.02)$, fasting insulin $(P=0.004)$, homeostatic model assessment of insulin resistance (HOMA-IR) $(P=0.002)$ and lower high density lipoprotein $(\mathrm{HDL})$ cholesterol $(P<0.001)$ levels. After $5.63 \pm 2.6$ months of testosterone treatment, the BMI, WC $(P<0.001$ for both $)$, systolic blood pressure $(P=0.002)$ and triglyceride level $(P=0.04)$ were increased and the total and HDL cholesterol levels were decreased $(P=0.02$ and $P<0.001$ respectively).

Conclusions: This study shows increased prevalence of MS and unfavorable effects of testosterone replacement in young patients with $\mathrm{CHH}$. Long-term follow-up studies are warranted to investigate the cardiovascular safety of testosterone treatment in this specific population.
\end{abstract}

European Journal of Endocrinology $164759-764$

\section{Introduction}

Metabolic syndrome (MS) is a combination of various premorbid conditions contributing to the development of diabetes and cardiovascular disease. The components of MS which have been defined by several medical groups are the abnormal glucose metabolism, increased abdominal fat, high blood pressure, high triglycerides and low HDL levels (1). The more appropriate method would be to strictly control each of these MS components in order to prevent cardiovascular morbidity and mortality (2).

Hypogonadism, a prevalent clinical situation of the middle and older age population $(3,4)$, has been reported as a predictor of MS (5-7). However, the majority of the data showing the association between MS and hypogonadism originate from the obese or elderly population with chronic metabolic disorders (8-15). Aging, obesity, chronic disorders and several medications commonly used in daily practice can decrease serum testosterone levels (16-22) and confound the association between hypogonadism and MS. Thus, the unconfounded data of the patients with congenital hypogonadal hypogonadism (CHH) are of utmost importance, as they can provide information about the effects of low testosterone levels on metabolic profiles. High fasting glucose and insulin levels in young men with $\mathrm{CHH}(23,24)$ were reported in two small studies. However, there is no data about the other components of MS in this specific population.

Testosterone replacement is an emerging treatment option for the metabolic abnormalities in patients with hypogonadism $(25,26)$. However, not all the data is in favor of the benefits of testosterone replacement. Some reports mention that testosterone improves metabolic parameters (27-32), while others do not confirm these data (33-38). Inhomogenities of the study populations, different formulas and follow-up periods and several other confounders such as concomitant drugs or metabolic disorders may be the reasons for these controversies. 
Our aim was to search for the prevalence of MS and its components in an unconfounded population of hypogonadism. For this reason, we retrospectively evaluated our database and selected young and treatment-naïve men with $\mathrm{CHH}$. We also searched for the effect of standard dosage of injectable testosterone ester replacement on the metabolic profiles of these patients.

\section{Materials and methods}

This retrospective analysis was performed by evaluating the database of the Department of Endocrinology and Metabolism, Gulhane Military Medical Academy School of Medicine, Ankara, Turkey. Military service is compulsory for every young man in Turkey and Gulhane School of Medicine is the tertiary medical center for all the military recruits. A total of 1586 hypogonadal patients were registered between the years 2000 and 2009. Of these, 653 patients were excluded due to previous history of androgen replacement, 214 patients were excluded due to higher testosterone levels $(200-300 \mathrm{ng} / \mathrm{dl}), 28$ patients were excluded due to liver, kidney or pulmonary diseases, 76 patients were excluded because of diagnosis other than hypogonadotropic hypogonadism (i.e. primary hypogonadism, panhypopituitarism, pituitary adenoma) and 283 were excluded because of incomplete data about the demographic and the metabolic parameters. Finally, 332 treatment-naïve patients (age $21.68 \pm 2.09$ years) with $\mathrm{CHH}$ were included in the study. The control group included 395 age- and body mass index (BMI)-matched healthy recruits (age 21.39 \pm 1.49 years). None of the control subjects had any chronic disorders. All subjects gave informed consent and the Local Ethical Committee of Gulhane School of Medicine approved the study. This study is registered with ClinicalTrials.gov, number NCT01160341.

The height, weight and waist circumference (WC) of the patients and control subjects were measured with their underwear. BMI was computed as the ratio of weight to the square of height $\left(\mathrm{kg} / \mathrm{m}^{2}\right)$. WC was measured, after the patients exhaled, from the line on the iliac crest which is parallel to the ground. Blood pressure of the patients was measured with an appropriate arm cuff and a mercury column sphygmomanometer, after a resting period of at least $5 \mathrm{~min}$. The mean of the two sitting measurements was used as the systolic and diastolic blood pressure of the patients and controls. Pubertal developments of the patients were assessed according to the Tanner stages. The diagnosis of $\mathrm{CHH}$ was based on a failure to undergo spontaneous puberty before 18 years of age and was confirmed by low serum total testosterone levels and normal or low gonadotropin levels. Additional criteria were the absence of a pituitary or hypothalamic mass lesion on magnetic resonance imaging, presence of a gonadotropin response to repetitive doses of GNRH and a normal karyotype (46, XY).
MS was defined according to the National Cholesterol Education Program's Adult Treatment Panel III report, as having any three of the following criteria (WC $>102 \mathrm{~cm}$, triglycerides $150 \mathrm{mg} / \mathrm{dl}$, HDL cholesterol $<40 \mathrm{mg} / \mathrm{dl}$, blood pressure $130 / 85 \mathrm{mg} / \mathrm{dl}$, fasting blood glucose $100 \mathrm{mg} / \mathrm{dl}$ ) (39).

\section{Laboratory measurements}

For biochemical analyses, all blood samples were collected from the antecubital vein, between 0800 and $0900 \mathrm{~h}$. after an overnight fasting. The samples were centrifuged for $15 \mathrm{~min}$ at $2000 \boldsymbol{g}$, aliquoted and immediately frozen at $-80{ }^{\circ} \mathrm{C}$ for analyses. Fasting plasma glucose, total cholesterol, triglyceride, and highdensity lipoprotein cholesterol levels were measured by the enzymatic colorimetric method with Olympus AU2700 auto analyzer using reagents from Olympus Diagnostics (GmbH, Hamburg, Germany). Low-density lipoprotein cholesterol (LDL-C) was calculated by Friedewald's formula (40). The serum basal insulin level and testosterone were measured by the electrochemiluminescence method with Modular Analytics E170 autoanalyzer using reagents from Roche Diagnostics. Insulin sensitivity was calculated by using the HOMA index by the formula, HOMA-IR $=($ insulin $\times$ glucose)/405 (41).

\section{Testosterone replacement therapy}

Follow-up data was available for the 208 patients who were treated with oil-based injectable blend of four esterized testosterone compounds (Sustanon $250 \mathrm{mg}$; $30 \mathrm{mg}$ testosterone propionate, $60 \mathrm{mg}$ testosterone phenylpropionate, $60 \mathrm{mg}$ testosterone isocaproate and $100 \mathrm{mg}$ testosterone decanoate) injected for 3 weeks. Some of the patients were not included in the follow-up study, as they were treated with different regimens (i.e. human chorionic gonadotropin in different dosage and periods with or without testosterone compounds; $n=82$ ). Also, some patients, who were living in the distant regions of the country, were not enrolled in the follow-up study, as they were not able to return for the control visits $(n=42)$. The blood samples for the evaluation of the baseline metabolic parameters were taken before the first testosterone injection. The patients were then reevaluated in the 3rd and/or 6th months of treatment. The follow-up visits were arranged on the days before the next testosterone injection. Therefore, the time points for taking the blood samples were similar for all the patients.

\section{Statistical analysis}

All data were recorded on a computer database and analyzed using SPSS 11.0 package program (SPSS, Inc., Chicago, IL, USA). Results are expressed as mean \pm s.D. 
Table 1 The metabolic profiles of the patients with hypogonadism and healthy volunteers.

\begin{tabular}{lllc}
\hline & $\begin{array}{l}\text { Patients } \\
(n=332)\end{array}$ & $\begin{array}{l}\text { Controls } \\
(n=395)\end{array}$ & $\boldsymbol{P}$ \\
\hline Age (years) & $21.8 \pm 2.4$ & $21.7 \pm 1.5$ & 0.43 \\
BMl (kg/m $\left.{ }^{2}\right)$ & $21.9 \pm 3.59$ & $21.9 \pm 1.01$ & 0.91 \\
WC $(\mathrm{cm})$ & $82.6 \pm 10.9$ & $76.6 \pm 4.56$ & $<0.001$ \\
SBP $(\mathrm{mmHg})$ & $113 \pm 10.1$ & $107 \pm 10.9$ & $<0.001$ \\
DBP (mmHg) & $73.1 \pm 8.46$ & $67.6 \pm 9.25$ & $<0.001$ \\
Total chol (mg/dl) & $155 \pm 29.3$ & $141 \pm 27.0$ & $<0.001$ \\
HDL chol (mg/dl) & $46.1 \pm 11.0$ & $52.6 \pm 8.7$ & $<0.001$ \\
LDL chol (mg/dl) & $89.3 \pm 25.1$ & $72.6 \pm 23.5$ & $<0.001$ \\
TG (mg/dl) & $89.0(68.0-123.0)$ & $69.4(54.5-90.7)$ & $<0.001$ \\
FBG (mg/dl) & $85.9 \pm 9.32$ & $84.4 \pm 7.28$ & 0.02 \\
Insulin $(\mu \mathrm{U} / \mathrm{ml})^{\mathrm{a}}$ & $9.41(6.45-13.2)$ & $7.62(5.23-9.23)$ & 0.004 \\
HOMA-IR & $2.04(1.32-2.77)$ & $1.53(1.05-1.91)$ & 0.002 \\
\hline
\end{tabular}

${ }^{\mathrm{a}}$ Results are given as mean (25-75\%).

Kolmogorov-Smirnov test was used to determine the distribution characteristics of variables and Levene's test was used to evaluate the equality of variance. Intra-group changes at two time points were analyzed by paired samples $t$-test or Wilcoxon signed-rank test as appropriate. Inter-group differences were analyzed by $\chi^{2}$ test, Student's $t$-test and Mann-Whitney $U$ test as appropriate. Differences were considered significant at $P<0.05$.

\section{Results}

The characteristics of the patients and the control subjects are given in Table 1 . The metabolic parameters of both the patients and the age- and BMI-matched control subjects were within the normal reference limits. However, when the two groups were compared, the patients with $\mathrm{CHH}$ had significantly higher systolic and diastolic blood pressure, WC, triglycerides, total and LDL cholesterol $(P<0.001$ for all), fasting blood glucose (FBG; $P=0.02)$ and insulin levels $(P=0.004)$ and HOMA indexes $(P=0.002)$ and significantly lower HDL cholesterol levels $(P<0.001)$. Both groups were also compared according to the presence of MS criteria. The patients with $\mathrm{CHH}$ had significantly higher prevalence of MS and its components when compared to those of the control subjects $(P<0.001$; Fig. 1).

\section{The effect of androgen replacement}

The follow-up data was available for the 208 patients treated with testosterone ester injection. No significant side effects were reported during the study period. The alterations of the metabolic parameters after a mean follow-up period of $5.63 \pm 2.6$ months are given in Table 2. According to the results, the BMI, WC $(P<0.001$ for both), systolic blood pressure (SBP; $P=0.002)$ and triglyceride levels $(P=0.04)$ were increased and the total and HDL cholesterol levels were decreased significantly $(P=0.02$ and $P<0.001$ respectively). On the other hand, there were no significant alterations in the fasting blood glucose, insulin, HOMA-IR, LDL cholesterol and diastolic blood pressure (DBP) levels. After the treatment period, the mean Tanner stages of the patients were significantly increased from $2.15 \pm 0.76$ to $3.23 \pm 0.91(P<0.001)$.

The alterations in plasma testosterone levels were significantly correlated with the alterations in BMI $(r=0.215, P=0.002)$, WC $(r=0.169, P=0.03)$ and HDL cholesterol $(r=-0.188, P=0.02)$ levels of the patients.

\section{Discussion}

According to the results, the metabolic parameters of the young and treatment-naïve patients with hypogonadism were within the normal reference ranges of the adult population. However, when compared with ageand BMI-matched healthy control subjects, the prevalence of $\mathrm{MS}$ and its components were significantly higher in the $\mathrm{CHH}$ group. The patients with $\mathrm{CHH}$ have significantly higher WC, blood pressure, fasting glucose, insulin and triglycerides and significantly lower HDL cholesterol levels in comparison to the healthy control subjects. About 6 months of treatment with oil-based injectable blend of four esterized testosterone compounds (Sustanon $250 \mathrm{mg}$ i.m.) did not improve the metabolic profiles but increased the WCs, systolic blood pressure, triglycerides and decreased the HDL and total cholesterol levels. The implications of the increased prevalence of MS in hypogonadism and the unexpected deterioration of the metabolic profiles after the testosterone replacement are discussed below.

There seems to be an interrelationship between hypogonadism and MS (25). Several cross-sectional studies report increased prevalence of hypogonadism in MS $(8,9,11)$, while many others report increased prevalence of MS and diabetes mellitus in subjects with lower testosterone levels (12-15). The increased MS risk in hypogonadism can be explained by several mechanisms. Low testosterone levels increase fat mass and decrease lean muscle, causing insulin resistance and hyperlipidemia (42). Also, the plasma triglyceride clearance may decrease due to the reduced testosterone/estrogen ratio (43). However, the majority of the reports about the association between MS and

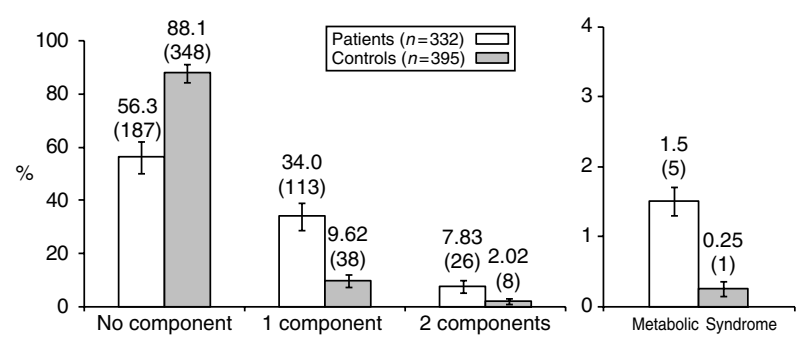

Figure 1 The prevalence of the components of metabolic syndrome in patients and healthy controls given as $\%(n)$. 
Table 2 The effect of androgen replacement on the components of metabolic syndrome.

\begin{tabular}{|c|c|c|c|}
\hline & $\begin{array}{l}\text { Before treatment } \\
(n=208)\end{array}$ & $\begin{array}{l}\text { After treatment } \\
(n=208)\end{array}$ & $\boldsymbol{P}$ \\
\hline BMI $\left(\mathrm{kg} / \mathrm{m}^{2}\right)$ & $22.0 \pm 3.59$ & $23.1 \pm 3.44$ & $<0.001$ \\
\hline$W C(\mathrm{~cm})$ & $82.7 \pm 10.9$ & $85.7 \pm 9.9$ & $<0.001$ \\
\hline Tanner stage & $2.15 \pm 0.76$ & $3.23 \pm 0.91$ & $<0.001$ \\
\hline $\mathrm{SBP}(\mathrm{mmHg})$ & $112 \pm 10.6$ & $115 \pm 10.2$ & 0.002 \\
\hline DBP $(\mathrm{mmHg})$ & $72.1 \pm 8.16$ & $72.8 \pm 8.42$ & 0.19 \\
\hline Total chol $(\mathrm{mg} / \mathrm{dl})$ & $156 \pm 29.9$ & $151 \pm 29.6$ & 0.02 \\
\hline HDL chol (mg/dl) & $46.4 \pm 11.4$ & $42.6 \pm 10.1$ & $<0.001$ \\
\hline LDL cho (mg/dl) & $89.1 \pm 25.5$ & $88.6 \pm 25.7$ & 0.79 \\
\hline $\mathrm{TG}(\mathrm{mg} / \mathrm{dl})^{\mathrm{a}}$ & $89.0(68.0-124.0)$ & $99.0(79.5-132.5)$ & 0.04 \\
\hline FBG (mg/dl) & $86.4 \pm 8.97$ & $85.4 \pm 10.3$ & 0.28 \\
\hline Insulin $(\mu \mathrm{U} / \mathrm{ml})^{\mathrm{a}}$ & $9.79(6.8-13.7)$ & $9.2(\overline{7} .3-13.8)$ & 0.25 \\
\hline HOMA-IR ${ }^{\mathrm{a}}$ & $2.04(1.32-2.78)$ & $2.00(1.51-2.06)$ & 0.11 \\
\hline $\begin{array}{l}\text { Total testosterone } \\
(\mathrm{ng} / \mathrm{dl})^{\mathrm{a}}\end{array}$ & $33.6(21-43)$ & $215(59-281)$ & $<0.001$ \\
\hline
\end{tabular}

${ }^{\mathrm{a}}$ Results are given as mean (25-75\%).

hypogonadism are from the elderly or obese populations with chronic disorders $(8-15)$. During the ageing process, testosterone levels constantly decrease, independent of the other clinical variables $(16,17)$. Moreover, adiposity augments the aromatization of testosterone to estradiol, reducing LH secretion and testosterone levels (18). Obesity also increases glucocorticoid turnover (19), which disturbs the regulation of the hypothalamic-pituitary-adrenal axis (44) and contributes to hypoandrogenism. Also, in most of these reports, the study populations were using chronic medications with the potentials to affect the serum testosterone levels (20-22). In this regard, the data from patients with $\mathrm{CHH}$ are of utmost importance, as they may reflect the unconfounded effects of low testosterone levels on metabolic profiles. To our knowledge, there are only two small studies, both of which report higher fasting glucose and insulin levels in young men with $\mathrm{CHH}$, without mentioning the other components of MS $(23,24)$. Thus, our data are noteworthy as they show poor metabolic parameters in a sizeable group of treatment-naïve patients with $\mathrm{CHH}$, mentioning that hypogonadism can cause MS even in very young ages.

Testosterone replacement is expected to improve the metabolic abnormalities in patients with hypogonadism (25), and for some authors, it may be a novel treatment option in MS (26). However, reports about the metabolic effects of testosterone replacement are controversial. Several studies mention that testosterone replacement improves fasting glucose levels $(27,28)$, insulin sensitivity $(27,29,30)$, arterial blood pressure (31, 32) and total cholesterol levels (27). However, many other studies also show that the effect of androgen replacement on metabolic parameters is either insignificant $(33,34)$ or unfavorable (35-38). Recently, a prospective study in the elderly hypogonadal men was terminated due to the increased cardiovascular mortality in the testosterone replacement arm (45). However, another prospective randomized study with a similar design (46) and two recent metanalyses of randomized controlled studies $(34,47)$ did not show any increase in cardiovascular events. Several reasons can be recalled for the discrepancies, such as different durations, formulations and dosages of androgens and concomitant metabolic disorders and medications $(48,49)$. So far, there is hardly enough data about the effects of standard testosterone regimens on young, previously untreated $\mathrm{CHH}$ patients without confounders. Two recent reports performed in small groups mention that testosterone supplementation improves insulin resistance without significantly affecting the blood lipids, arterial blood pressure or WC $(23,24)$. However, our results do not support these data and show increased WC, systolic blood pressure and decreased total and HDL cholesterol levels in the study group. We suggest that the size of the study population may be the main factor for the testosterone-induced alterations to become significant. Supportive to our data, a latest metanalysis of randomized controlled studies has also shown that testosterone therapy causes a small but significant decrease in HDL cholesterol levels (47).

The increased arterial blood pressure, triglyceride levels and decreased HDL cholesterol levels due to testosterone replacement may have the potential to cause adverse cardiovascular effects. However, so far, there is no long-term follow-up data that show increased cardiovascular events in this specific population. On the other hand, several reports mention that the decrease in HDL cholesterol levels may not be a harmful effect of testosterone replacement. It has been hypothesized that testosterone leads to trafficking of the cholesterol back from the peripheral tissues to the liver, leading to consumption of HDL. This decrease in HDL cholesterol levels due to testosterone replacement is suggested to exert anti-atherogenic rather than proatherogenic effects (50). Moreover, the decrease in total testosterone levels, which has also been shown in previous studies (27), may be regarded as an evidence of the favorable effects of testosterone regiments. It was also reported that the decrease in HDL cholestrol levels after testosterone replacement was due to the decrease in the least atherogenic $\mathrm{HDL}_{3}$ subfraction (51). However, our data cannot verify the above theory, as we have not analyzed the HDL subfractions.

This study may have several limitations. The retrospective design has handicaps compared with a randomized, placebo controlled prospective study. Still, our database provided a large group of young and treatment-naïve $\mathrm{CHH}$ patients, which is very helpful to recognize the effect of hypogonadism and its treatment on metabolic parameters. Another limitation may be the formulation of the testosterone regimen. Testosterone ester injections can increase serum testosterone to supraphysiological levels, which may be responsible for the adverse effects on systolic blood pressure and plasma lipids (48). However, two recent randomized, controlled studies, which have also reported decreased HDL 
cholesterol levels were performed by using daily transdermal gels (37) or testosterone tablets (38). Therefore, the drug formulation may not be the only reason for the worsening of the metabolic profiles. On the other hand, the alterations in the metabolic parameters, although statistically significant, are minor and may not be clinically important.

In conclusion, the present study has two significant findings. The first one is the increased prevalence of MS and its components in young $\mathrm{CHH}$ patients than the healthy control subjects. The second finding is the deterioration of systolic blood pressure, triglycerides and HDL cholesterol levels along with the lowering of total cholesterol levels due to testosterone replacement. These data may be of help to recognize that testosterone replacement may cause unfavorable metabolic effects in young hypogonadal patients. However, whether these metabolic alterations will result in adverse cardiovascular outcomes in the long term is not clear. Prospective studies are needed to find out the long-term effects of testosterone replacement on cardiovascular morbidity and mortality in this specific population.

\section{Declaration of interest}

The authors declare that there is no conflict of interest that would prejudice the impartiality of this scientific work.

\section{Funding}

This research did not receive any specific grant from any funding agency in the public, commercial or not-for-profit sector.

\section{References}

1 Alberti KG, Eckel RH, Grundy SM, Zimmet PZ, Cleeman JI, Donato KA, Fruchart JC, James WP, Loria CM \& Smith SC Jr. Harmonizing the metabolic syndrome: a joint interim statement of the International Diabetes Federation Task Force on Epidemiology and Prevention; National Heart, Lung, and Blood Institute; American Heart Association; World Heart Federation; International Atherosclerosis Society; and International Association for the Study of Obesity. Circulation 200920 1640-1645. (doi:10. 1161/CIRCULATIONAHA.109.192644)

2 Obunai K, Jani S \& Dangas GD. Cardiovascular morbidity and mortality of the metabolic syndrome. Medical Clinics of North America 200791 1169-1184. (doi:10.1016/j.mcna.2007.06.003)

3 Araujo AB, O'Donnell AB, Brambilla DJ, Simpson WB, Longcope C, Matsumoto AM \& McKinlay JB. Prevalence and incidence of androgen deficiency in middle-aged and older men: estimates from the Massachusetts Male Aging Study. Journal of Clinical Endocrinology and Metabolism 200489 5920-5926. (doi:10. 1210/jc.2003-031719)

4 Mulligan T, Frick MF, Zuraw QC, Stemhagen A \& McWhirter C. Prevalence of hypogonadism in males aged at least 45 years: the HIM study. International Journal of Clinical Practice $2006 \mathbf{6 0}$ 762-769. (doi:10.1111/j.1742-1241.2006.00992.x)

5 Laaksonen DE, Niskanen L, Punnonen K, Nyyssönen K, Tuomainen TP, Valkonen VP, Salonen R \& Salonen JT. Testosterone and sex hormone binding globulin predict the metabolic syndrome and diabetes mellitus in middle-aged men. Diabetes Care 200427 1036-1041. (doi:10.2337/diacare.27.5.1036)
6 Kupelian V, Page ST, Araujo AB, Travison TG, Bremner WJ \& McKinlay JB. Low sex hormone-binding globulin, total testosterone, and symptomatic androgen deficiency are associated with development of the metabolic syndrome in nonobese men. Journal of Clinical Endocrinology and Metabolism 200691 843-850. (doi:10.1210/jc.2005-1326)

7 Stellato RK, Feldman HA, Hamdy O, Horton ES \& McKinlay JB. Testosterone, sex hormone-binding globulin, and the development of type 2 diabetes in middle-aged men: prospective results from the Massachusetts Male Aging Study. Diabetes Care 200023 490-494. (doi:10.2337/diacare.23.4.490)

8 Dhindsa S, Miller MG, McWhirter CL, Mager DE, Ghanim H, Chaudhuri A \& Dandona P. Testosterone concentrations in diabetic and nondiabetic obese men. Diabetes Care 201033 1186-1192. (doi:10.2337/dc09-1649)

9 Muller M, Grobbee DE, den Tonkelaar I, Lamberts SW \& van der Schouw YT. Endogenous sex hormones and metabolic syndrome in aging men. Journal of Clinical Endocrinology and Metabolism 2005 90 2618-2623. (doi:10.1210/jc.2004-1158)

10 Kuk JL \& Ardern CI. Age and sex differences the clustering of metabolic syndrome factors: association with mortality risk. Diabetes Care, 2010. (doi:10.2337/dc10-0942)

11 Blouin K, Després JP, Couillard C, Tremblay A, Prud'homme D, Bouchard C \& Tchernof A. Contribution of age and declining androgen levels to features of the metabolic syndrome in men. Metabolism 200554 1034-1040. (doi:10.1016/j.metabol.2005. 03.006)

12 Phillips GB. Relationship between serum sex hormones and glucose, insulin and lipid abnormalities in men with myocardial infarction. PNAS 1977 74 1729-1733. (doi:10.1073/pnas.74.4. 1729)

13 Phillips GB. Relationship between serum sex hormones and the glucose-insulin-lipid defect in men with obesity. Metabolism 1993 42 116-120. (doi:10.1016/0026-0495(93)90181-M)

14 Haffner SM. Sex hormones, obesity, fat distribution, type 2 diabetes and insulin resistance: epidemiological and clinical correlation. International Journal of Obesity and Related Metabolic Disorders 2000 24 56-58. (doi:10.1038/sj/ijo/0801279)

15 Laaksonen DE, Niskanen L, Punnonen K, Nyyssönen K, Tuomainen T-P, Salonen R, Rauramaa R \& Salonen JT. Sex hormones, inflammation and the metabolic syndrome: a population-based study. European Journal of Endocrinology 2003149 601-608. (doi:10.1530/eje.0.1490601)

16 Harman SM, Metter EJ, Tobin JD, Pearson J \& Blackman MR. Longitudinal effects of aging on serum total and free testosterone levels in healthy men. Baltimore Longitudinal Study of Aging. Journal of Clinical Endocrinology and Metabolism $2001 \mathbf{8 6}$ 724-731. (doi:10.1210/jc.86.2.724)

17 Wu FC, Tajar A, Beynon JM, Pye SR, Silman AJ, Finn JD, O'Neill TW, Bartfai G, Casanueva FF, Forti G, Giwercman A, Han TS, Kula K, Lean ME, Pendleton N, Punab M, Boonen S, Vanderschueren D, Labrie F \& Huhtaniemi IT; EMAS Group. Identification of late-onset hypogonadism in middle-aged and elderly men. New England Journal of Medicine 2010 363 123-135. (doi:10.1056/NEJMoa0911101)

18 Jones TH. Hypogonadism in men with type 2 diabetes. Practical Diabetes International 200724 269-277. (doi:10.1002/pdi.1117)

19 Stewart PM, Boulton A, Kumar S, Clark PMS \& Shackleton CHL. Cortisol metabolism in human obesity: impaired cortisone 3 cortisol conversion in subjects with central adiposity. Journal of Clinical Endocrinology and Metabolism 199984 1022-1027. (doi:10.1210/jc.84.3.1022)

20 Corona G, Boddi V, Balercia G, Rastrelli G, De Vita G, Sforza A, Forti G, Mannucci E \& Maggi M. The effect of statin therapy on testosterone levels in subjects consulting for erectile dysfunction. Journal of Sexual Medicine 20107 1547-1556. (doi:10.1111/j. 1743-6109.2009.01698.x)

21 Stanworth RD, Kapoor D, Channer KS \& Jones TH. Statin therapy is associated with lower total but not bioavailable or free testosterone in men with type 2 diabetes. Diabetes Care 200932 541-546. (doi:10.2337/dc08-1183) 
22 Fogari R, Preti P, Derosa G, Marasi G, Zoppi A, Rinaldi A \& Mugellini A. Effect of antihypertensive treatment with valsartan or atenolol on sexual activity and plasma testosterone in hypertensive men. European Journal of Clinical Pharmacology 200258 177-180. (doi:10.1007/s00228-002-0456-3)

23 Wu XY, Mao JF, Lu SY, Zhang Q \& Shi YF. Testosterone replacement therapy improves insulin sensitivity and decreases high sensitivity C-reactive protein levels in hypogonadotropic hypogonadal young male patients. Chinese Medical Journal 2009 5 2846-2850. (doi:10.3760/cma.j.issn.0366-6999.2009.23.008)

24 Naharci MI, Pinar M, Bolu E \& Olgun A. Effect of testosterone on insulin sensitivity in men with idiopathic hypogonadotropic hypogonadism. Endocrine Practice 200713 629-635.

25 Guay AT. The emerging link between hypogonadism and metabolic syndrome. Journal of Andrology 200930 370-376. (doi:10.2164/jandrol.108.006015)

26 Makhsida N, Shah J, Yan G, Fisch H \& Shabsigh R. Hypogonadism and metabolic syndrome: implications for testosterone therapy. Journal of Urology $2005 \mathbf{1 7 4}$ 827-834. (doi:10.1097/01.ju. 0000169490.78443.59)

27 Kapoor D, Goodwin E, Channer KS \& Jones TH. Testosterone replacement therapy improves insulin resistance, glycemic control, visceral adiposity and hypercholesterolaemia in hypogonadal men with type 2 diabetes. European Journal of Endocrinology 2006154 899-906. (doi:10.1530/eje.1.02166)

28 Boyanov MA, Boneva Z \& Christov VG. Testosterone supplementation in men with type 2 diabetes, visceral obesity and partial androgen deficiency. Aging Male 20036 1-7.

29 Marin P, Holmang S, Jonsson L, Sjostrom L, Kvist H, Holm G, Lindstedt G \& Bjorntorp P. The effects of testosterone treatment on body composition and metabolism in middle-aged obese men. International Journal of Obesity and Related Metabolic Disorders 1992 16 991-997.

30 Marin P, Holmang S, Gustafsson C, Jonsson L, Kvist H, Elander A, Eldh J, Sjöström L, Holm G \& Björntorp P. Androgen treatment of abdominally obese men. Obesity Research 19931 245-251.

31 Marin P. Testosterone and regional fat distribution. Obesity Research $19953609-612$.

32 Li JY, Zhu JC, Dou JT, Bai WJ, Deng SM, Li M, Huang W \& Jin H. Effects of androgen supplementation therapy on partial androgen deficiency in the aging male: a preliminary study. Aging Male 2002 5 47-51. (doi:10.1080/tam.5.1.47.51)

33 Liu PY, Wishart SM, Celermajer DS, Jimenez M, Pierro ID, Conway AJ \& Handelsman DJ. Do reproductive hormones modify insulin sensitivity and metabolism in older men? A randomized, placebo controlled clinical trial of recombinant human chorionic gonadotropin European Journal of Endocrinology 2003148 55-66. (doi:10.1530/eje.0.1480055)

34 Haddad RM, Kennedy CC, Caples SM, Tracz MJ, Boloña ER, Sideras K, Uraga MV, Erwin PJ \& Montori VM. Testosterone and cardiovascular risk in men: a systematic review and meta-analysis of randomized placebo-controlled trials. Mayo Clinic Proceedings 200782 29-39. (doi:10.4065/82.1.29)

35 Dobs AS, Bachorik PS, Arver S, Meikle AW, Sanders SW, Caramelli KE \& Mazer NA. Interrelationships among lipoprotein levels, sex hormones, anthropometric parameters, and age in hypogonadal men treated for 1 year with a permeation-enhanced testosterone transdermal system. Journal of Clinical Endocrinology and Metabolism 200186 1026-1033. (doi:10.1210/jc.86.3.1026)

36 Wittert GA, Chapman IM, Haren MT, Mackintosh S, Coates P \& Morley JE. Oral testosterone supplementation increases muscle and decreases fat mass in healthy elderly males with low-normal gonadal status. Journal of Clinical Endocrinology and Metabolism 200186 1026-1033. (doi:10.1210/jc.86.3.1026)

37 Basaria S, Coviello AD, Travison TG, Storer TW, Farwell WR, Jette AM, Eder R, Tennstedt S, Ulloor J, Zhang A, Choong K, Lakshman KM, Mazer NA, Miciek R, Krasnoff J, Elmi A, Knapp PE, Brooks B, Appleman E, Aggarwal S, Bhasin G, Hede-Brierley L, Bhatia A, Collins L, LeBrasseur N, Fiore LD \& Bhasin S. Adverse events associated with testosterone administration. New England Journal of Medicine 2010 8 109-122. (doi:10.1056/NEJMoa1000485)
38 Emmelot-Vonk MH, Verhaar HJ, Nakhai Pour HR, Aleman A, Lock TM, Bosch JL, Grobbee DE \& van der Schouw YT. Effect of testosterone supplementation on functional mobility, cognition, and other parameters in older men: a randomized controlled trial. Journal of the American Medical Association 20082 39-52. (doi:10. 1001/jama.2007.51)

39 Third report of the National Cholesterol Education Program (NCEP). Expert panel on detection, evaluation, and treatment of high blood cholesterol in adults (Adult Treatment Panel III). Final report. Circulation 2002106 3143-3421.

40 Friedewald WT, Levy RI \& Fredrickson DS. Estimation of the concentration of lowdensity lipoprotein cholesterol in plasma, without use of the preparative ultracentrifuge. Clinical Chemistry 197218 499-502.

41 Matthews DR \& Wallace TM. The assessment of insulin resistance in man. Diabetic Medicine 200219 527-534. (doi:10.1046/j. 1464-5491.2002.00745.x)

42 Dandona P, Dhindsa S, Chaudhuri A, Bhatia V, Topiwala S \& Mohanty P. Hypogonadotrophic hypogonadism in type 2 diabetes, obesity and the metabolic syndrome. Current Molecular Medicine 20088 816-828. (doi:10.2174/156652408786733658)

43 Urabe M, Kashiwagi T, Okubo T, Tsuchiya H, Iwasa K, Kikuchi N, Yokota K, Hosokawa K \& Honjo H. Effect of estrogen replacement therapy on hepatic triglyceride lipase, lipoprotein lipase and lipid including apolipoprotein $\mathrm{E}$ in climacteric and elderly women. Endocrine Journal 199643 737. (doi:10.1507/endocrj.43.737)

44 Rask E, Olsson T, Soderberg S, Andrew R, Livingstone DE, Johnson $\mathrm{O} \&$ Walker BR. Tissue-specific dysregulation of cortisol metabolism in human obesity. Journal of Clinical Endocrinology and Metabolism 2001 86 1418-1421. (doi:10.1210/jc.86.3.1418)

45 Laughlin GA, Barrett-Connor E \& Bergstrom J. Low serum testosterone and mortality in older men. Journal of Clinical Endocrinology and Metabolism 200893 68-75. (doi:10.1210/jc. 2007-1792)

46 Srinivas-Shankar U, Roberts SA, Connolly MJ, O'Connell MD, Adams JE, Oldham JA \& Wu FC. Effects of testosterone on muscle strength, physical function, body composition, and quality of life in intermediate-frail and frail elderly men: a randomized, doubleblind, placebo-controlled study. Journal of Clinical Endocrinology and Metabolism 2010 95 639-650. (doi:10.1210/jc.2009-1251)

47 Fernández-Balsells MM, Murad MH, Lane M, Lampropulos JF, Albuquerque F, Mullan RJ, Agrwal N, Elamin MB, GallegosOrozco JF, Wang AT, Erwin PJ, Bhasin S \& Montori VM. Adverse effects of testosterone therapy in adult men: a systematic review and meta-analysis. Journal of Clinical Endocrinology and Metabolism 201095 2560-2575. (doi:10.1210/jc.2009-2575)

48 Dandona P \& Rosenberg MT. A practical guide to male hypogonadism in the primary care setting. International Journal of Clinical Practice 201064 682-696. (doi:10.1111/j. 1742-1241.2010.02355.x)

49 Guay A, Seftel AD \& Traish A. Hypogonadism in men with erectile dysfunction may be related to a host of chronic illnesses. International Journal of Impotence Research 201022 9-19. (doi:10.1038/ijir.2009.46)

50 Langer C, Gansz B, Goepfert C, Engel T, Uehara Y, von Dehn G, Jansen H, Assmann G \& von Eckardstein A. Testosterone up-regulates scavenger receptor BI and stimulates cholesterol efflux from macrophages. Biochemical and Biophysical Research Communications 2002296 1051-1057. (doi:10.1016/S0006291X(02)02038-7)

51 Tan KC, Shiu SW, Pang RW \& Kung AW. Effects of testosterone replacement on HDL subfractions and apolipoprotein A-I containing lipoproteins. Clinical Endocrinology $1998 \mathbf{4 8}$ 187-194. (doi:10.1046/j.1365-2265.1998.3721211.x)

Received 24 January 2011

Accepted 16 February 2011 